\title{
27 Health insurance coverage and access to care among European elders: cross- national differences and social gradients
}

- Unmet health care needs and insufficient health insurance coverage still exist among European elders and vary widely across countries

- Insufficient access and lack of insurance coverage are most prevalent in poorer countries with low health care expenditures and in countries with large income inequalities

- Health insurance coverage and access to care are socially graded within almost all countries and may contribute to social inequalities in health status

\subsection{Access to health: a key dimension of social inclusion}

Pro-rich inequalities in health are a well-documented and ubiquitous phenomenon. They exist not only in poor countries but also in most (if not all) rich countries. Moreover, within countries, inequalities in health persist through the entire life-cycle, from the cradle to the grave.

Several explanations have been put forward to explain the persistent nature of the social gradient in health. For instance, better educated individuals have access to healthier jobs and greater autonomy in their jobs. Individuals with higher income can afford to buy healthier food, live in better housing and healthier environments. Last but not least, higher income can buy better access to health care or access to better health care. This mechanism is repeatedly stressed in the literature on social inequalities in health, which distinguishes between avoidable and unavoidable inequalities:

Disparities in health are avoidable to the extent that they stem from identifiable policy options exercised by governments, such as ... health care funding.

(Woodward \& Kawachi 2000)

According to this common definition, social differences in health that are caused by differences in access to health care are avoidable and often considered unjust. In fact, differences in access to care exist to varying degrees in all countries, independent of the way health care is generally financed. Tackling avoidable health 
inequalities has indeed long been high on the agenda in some countries (e.g. the UK), but less so in others (e.g. in Germany). Unfortunately, there has been little success so far - some policies even appear to widen the rich-poor gap in health due to differential uptake (for instance free access to preventative care).

Cross-national differences in health inequality have also been documented in the literature. Findings on differences in education- or income-related gradients such as those obtained from earlier SHARE waves (Jürges 2009, 2010) call for an explanation. In this chapter, I examine how access to health care - as a crucial dimension of social inclusion - varies across and within European countries. Specifically, I concentrate on income-related inequity in access to health care in SHARE Wave 5 among the elder population along three important dimensions: subjective unmet need as a measure of horizontal inequity, catastrophic out-ofpocket expenses for health care (relative to household income) as a measure of the financial burden, and satisfaction with basic health insurance coverage or the coverage in the national health system as an overall subjective measure of the health system performance in terms of access to care.

\subsection{Data and measurements}

The analyses presented in this study are based on data from SHARE Wave 5 (2012), covering some 64,000 respondents in 15 countries. Specifically, I rely on information collected in the health care module. This short but important module serves to facilitate international comparisons in two areas: (1) health care utilisation (in the last 12 months), including unmet need, and (2) health insurance coverage and out-of-pocket expenses. For cross-national comparisons we also add OECD data on income, income inequality and health expenditures (OECD 2014).

There are four items in SHARE Wave 5 to measure subjective unmet need. First, we asked respondents whether there "was a time in the past 12 months when" they "needed to see a doctor but could not because of cost". Four per cent of the respondents answered yes. Second, we asked whether they did not see a doctor when they needed one because they "had to wait too long". This applied to six per cent of the respondents overall. Then we also asked respondents whether they had "postponed visits to the dentist" in the last twelve months, to help keeping their living costs down (10\%) or whether they had "gone without or not replaced glasses" they needed because they could not afford new ones ( $8 \%)$. The last two items are also part of the social deprivation index used throughout this volume. At least one unmet need was reported by 17 per cent of the respondents.

Out-of-pocket (OOP) expenses are costs of health care that are not paid for or reimbursed by "third party payers", i.e. the national health system or a public 
or private health insurer, and that are thus borne by the patient him- or herself. Patients typically pay out-of-pocket for treatments or drugs that are not covered (e.g. because they are too expensive, or because they are not effective) or only partially covered (i.e. patients make co-payments). Insurance contracts also often stipulate a certain deductible, that is, patients pay the full costs of their treatment up to some amount. Only if costs exceed this amount, the health insurance or national health systems pays for the treatment, fully or partially.

SHARE has measured respondents' annual out-of-pocket expenses for five types of medical care or care related to illness: doctor visits, dentist visits including prostheses, prescription and over-the-counter drugs, hospital and other inpatient stays (incl. temporary stays in nursing homes), and at-home care (personal care, wheels-on-meals, etc.). Additionally, we asked for the amount of the annual deductible (if there was any). Out-of-pocket expenses are computed as the sum of deductibles paid, direct payments to health care providers and co-payments. Descriptive summary statistics for the entire SHARE sample are shown in Table 27.1.

Table 27.1: Health care utilisation and out-of-pocket expenses

\begin{tabular}{|c|c|c|c|c|}
\hline Type of care & $\begin{array}{l}\text { Per cent who } \\
\text { received type } \\
\text { of care }\end{array}$ & $\begin{array}{l}\text { Per cent who } \\
\text { paid OOP } \\
\text { conditional } \\
\text { on use }\end{array}$ & $\begin{array}{l}\text { Avg. OOP } \\
\text { expenses } \\
\text { conditional } \\
\text { on payment }\end{array}$ & $\begin{array}{l}\text { Avg. OOP } \\
\text { expenses } \\
\text { per sample } \\
\text { member }\end{array}$ \\
\hline Doctor visits & $89 \%$ & $44 \%$ & $221 €$ & $87 €$ \\
\hline Drugs $^{\text {a) }}$ & $75 \%$ & $76 \%$ & $213 €$ & $121 €$ \\
\hline Dentists & $55 \%$ & $75 \%$ & $520 €$ & $214 €$ \\
\hline Hospital/other inpatient & $16 \%$ & $46 \%$ & $441 €$ & $32 €$ \\
\hline At-home care & $11 \%$ & $62 \%$ & $1,775 €$ & $121 €$ \\
\hline Deductibles $^{\text {b) }}$ & & $21 \%$ & $329 €$ & $69 €$ \\
\hline Sum & & & & $645 €$ \\
\hline
\end{tabular}

Notes: a) Respondents who take drugs at least once a week, b) Per cent having a deductible and average annual deductible amounts, $\mathrm{N}=63,966$

Source: SHARE Wave 5 release 0 , author's own computations

For example 89 per cent of the sample have visited a doctor at least once in the last twelve months. Of those, 44 per cent had paid an average amount of $221 €$ outof-pocket. Overall, the average amount paid out of pocket was $645 €$ per person. To compare the financial burden of out-of-pocket expenses on households across countries, I have computed the percentage of annual household income spent out-of-pocket on health care. Across all countries, households in the SHARE samples spent on average 2.6 per cent of their net income on health care out-ofpocket. To obtain the full costs of health care one would also have to take insur- 
ance premia or social security contributions into account. However, these are not available in the data.

Although there is no generally accepted definition of catastrophic health care expenses, I use 15 per cent of net annual household income as threshold (see e.g. Wyszewianski 1986). According to this definition, three per cent of households with older adults aged 50 and over faced catastrophic out-of-pocket health care expenses in SHARE Wave 5.

One important innovation in SHARE Wave 5 was to ask respondents how satisfied they were with their own coverage in their basic (statutory) health insurance or national health system: very satisfied, satisfied, dissatisfied, or very dissatisfied. Overall, the level of satisfaction was quite high. 34 per cent of our respondents said they were very satisfied, and another 51 per cent said they were satisfied. Only 15 per cent of respondents were either dissatisfied (11\%) or very dissatisfied (4\%).

\subsection{Cross-national differences in out-of-pocket expenses, unmet need, and satisfaction with health insurance coverage}

In this section, I show a cross-national comparison of the level of health insurance coverage, or rather the lack of coverage, among European elders by describing differences in out-of-pocket expenses, unmet need, and dissatisfaction with health insurance coverage. Our data reveal substantial heterogeneity with respect to these three dimensions across SHARE countries. Figure 27.1 shows -by country - the percentage of respondents who mention at least one unmet need (Panel A), the percentage of households with catastrophic health care expenses (Panel B), and the percentage of respondents who say they are dissatisfied or even very dissatisfied with the coverage in their basic health insurance (Panel C).

Figure 27.1 contains many notable results. First, there is an enormous cross-national variation in terms of the three indicators. For instance, more than 50 per cent of respondents in Estonia reported at least one unmet need, whereas in the countries with the lowest levels of unmet need, the proportion is less than ten per cent. Nearly five per cent of Israeli households faced catastrophic health care expenses, in contrast to less than one per cent in Luxembourg. Furthermore, Italian respondents are least satisfied with the coverage in their National Health Service. More than one third of the Italian respondents claimed they were dissatisfied or even very dissatisfied with their basic coverage. In contrast, less than 


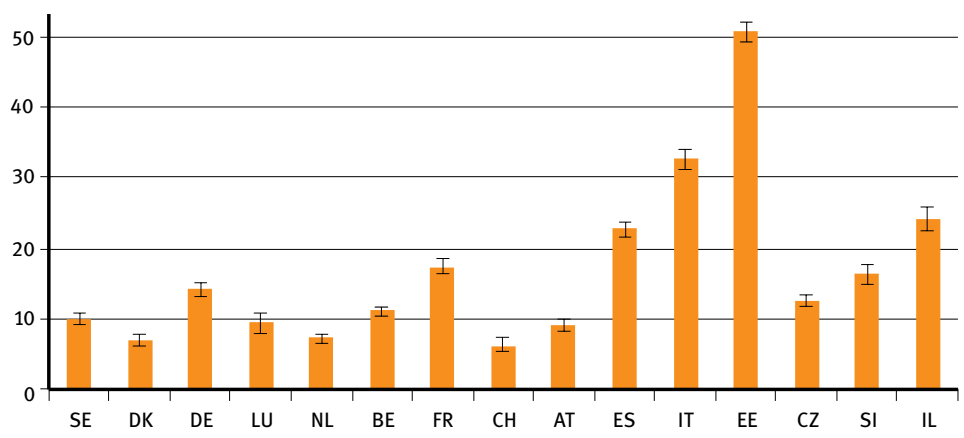

Panel A: Per cent with at least one unmet need

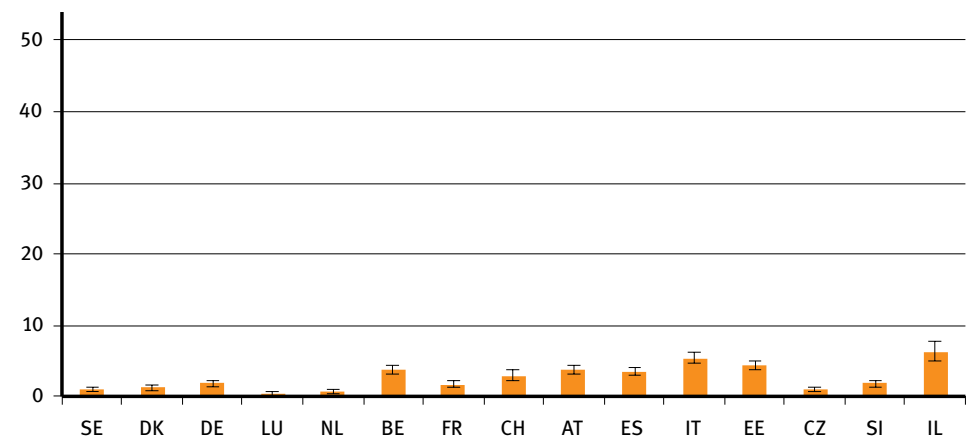

Panel B: Per cent with catastrophic OOP health expenses

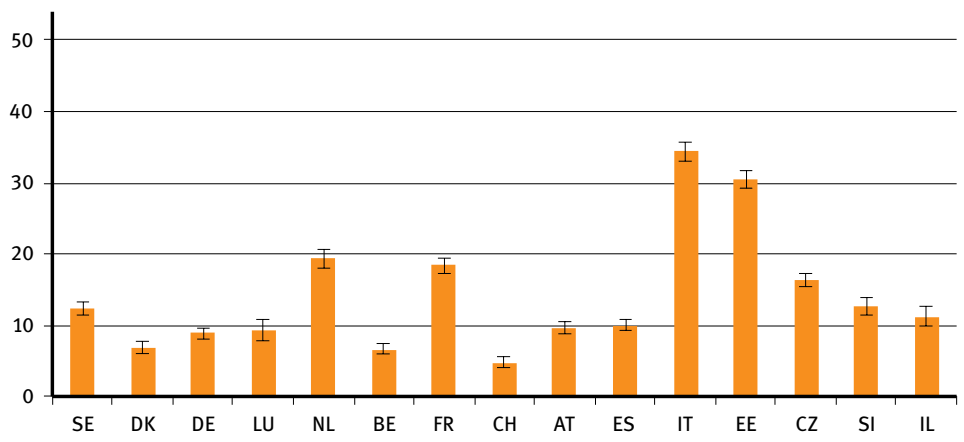

Panel C: Per cent with dissatisfied with basic HI coverage

Figure 27.1: Cross-national differences in health insurance coverage indicators, vertical lines show 95 per cent confidence intervals

Notes: $\mathrm{N}=63,966$

Source: SHARE Wave 5 release 0 , author's own computations 
five per cent of Swiss respondents (who hold an obligatory private health insurance) claimed to be dissatisfied.

On the one hand, there is some stability in terms of the position of a country in the three rankings. For instance, Italy and Estonia are always among the three worst performing countries. Denmark and Luxembourg are among the five best performing countries, independent of the chosen indicator. On the other hand, we find that Dutch respondents, who have a very small proportion of respondents reporting unmet need and few households with catastrophic health care expenses, are fairly dissatisfied with the coverage in their basic health insurance. In contrast, Israeli respondents who have high levels of unmet need and who relatively often live in households facing catastrophic out-of-pocket expenses are moderately satisfied with the coverage in their basic health insurance.

Figure 27.2 shows how our measures of health insurance coverage are related to

(a) median per capita income (in PPP-adjusted US-Dollar) as a measure of general economic prosperity,

(b) average health expenditure (in PPP-adjusted US-Dollar) as a measure of financial resources spent on health care

and

(c) the Gini-coefficient, as a measure of income inequality, a much cited possible source - on the societal level - of a wide array of health and social problems (Wilkinson \& Pickett 2009).

I use the country-level data as published by the OECD. The results for median per capita income and average health expenditure per capita are actually very similar because both indicators are highly correlated $(\mathrm{r}=0.88)$ and I will discuss results on health expenditure only.

As the graphs in the middle column of Figure 27.2 show, health care expenditures are negatively linked with the percentage of respondents who report at least one unmet need, the percentage of households who faced catastrophic health care expenses, and the percentage of respondents who are dissatisfied with their health insurance coverage. In other words, I find a fairly strong link between the resources spent on health care and various indicators of health care coverage.

The graphs in the right column of Figure 27.2 show that our indicators measuring the lack of health insurance coverage are positively linked with income inequality. Thus countries with generally more equally distributed incomes (and lower Gini coefficients) also have fewer individual elders who report unmet health care needs, have fewer households facing catastrophic health care expenses and have a lower proportion of elders who report dissatisfaction with their basic health insurance or national health system. 
Panel A: per cent with at least one unmet need
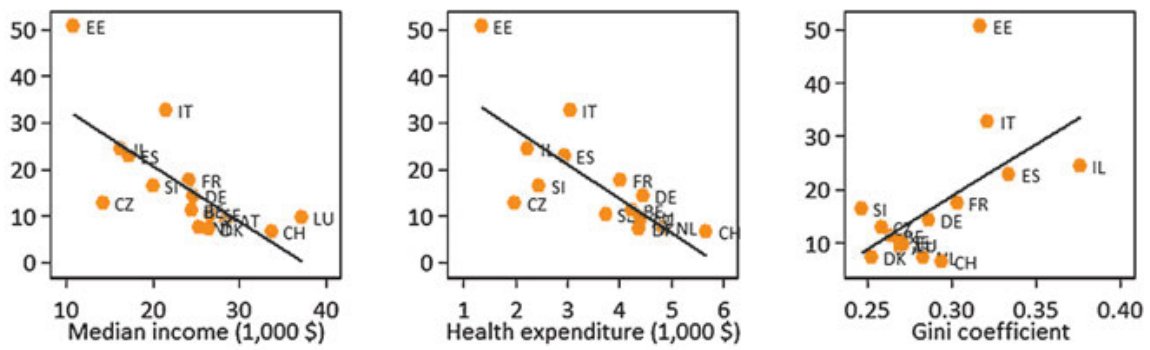

Panel B: per cent with catastropic OOP expenses
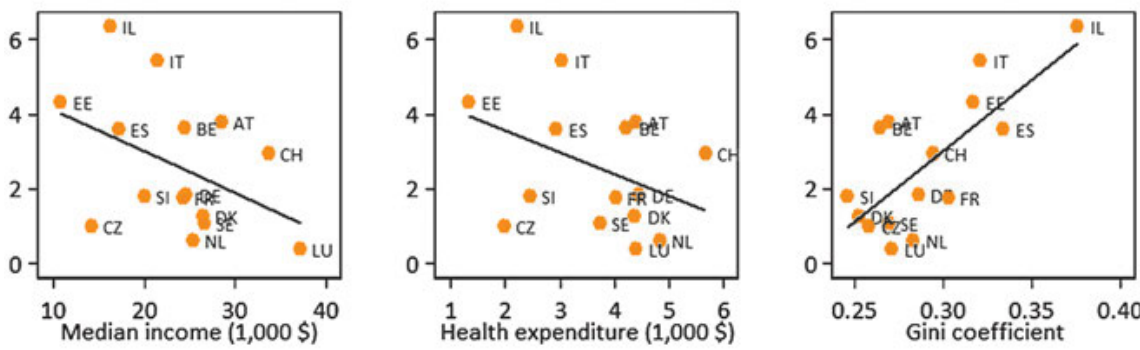

Panel C: per cent dissatisfied with health insurance coverage
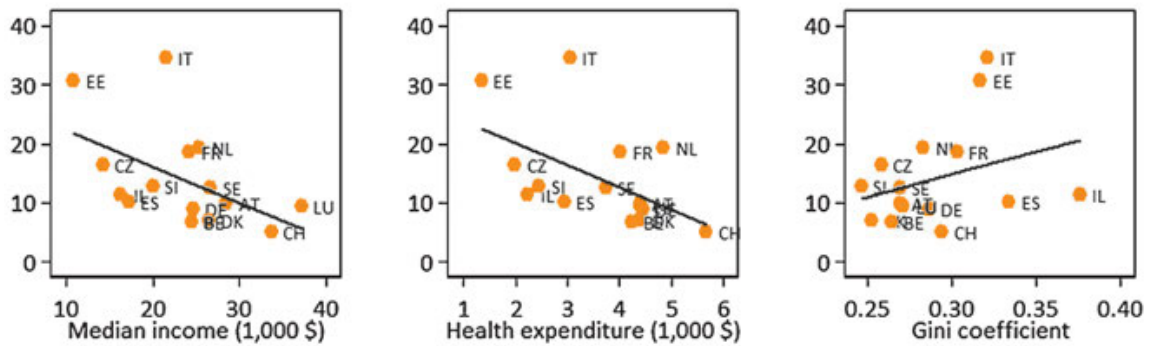

Figure 27.2: Cross-national correlation between macroeconomic indicators and health insurance coverage indicators

Notes: $\mathrm{N}=63,966$

Source: SHARE Wave 5 release 0 , author's own computations

Seven of the nine bivariate relationships shown in Figure 27.2 are statistically significant (also in multivariate regressions with health expenditure and the Gini coefficient simultaneously included). Only two are not statistically significant at the ten per cent level: the relationship between health expenditure and the pro- 
portion of households with catastrophic health care expenses and the relationship between income inequality and the percentage of dissatisfied respondents.

To summarise, the results shown in this section clearly demonstrate that access to care and health insurance coverage among the elders are linked with the economic prosperity of a country even within Europe. Richer countries that can afford to devote more resources in absolute terms to health care tend to provide better access to care and better health insurance coverage. Further, the data also clearly show that even given a country's income and health care expenditure level, less equal societies provide worse access to care and less health insurance coverage. This establishes another possible mechanism by which inequality per se may affect the health level of a society.

\subsection{Income-related inequality in health insurance coverage and access to care}

In this section, I show how - within the SHARE countries - unmet need, out-ofpocket expenses and satisfaction with health insurance coverage are linked with household income. To this end, I have classified each SHARE household according to their position in the within-country income distribution, i.e. to which income quintile they belong. For each of these quintiles, I have computed the proportion of respondents with at least one unmet need, the proportion facing catastrophic health care expenses and the proportion dissatisfied with their health insurance coverage.

Figure 27.3 shows income gradients for all countries combined. Notably, the relationship is in fact a gradient, because there are differences in access to care and health insurance coverage along the entire income distribution. We find significant pro-rich differences (with the exception of health insurance dissatisfaction) even between the richest and the second richest quintiles. Put differently, lack of access is not just a problem of poverty, i.e. a problem that can be simply explained by bad access among the poor.

Below, I will discuss how gradients differ between countries. To understand differences in inequality, one has to make a distinction between relative and absolute measures of inequality. To illustrate, I first discuss differences in inequality between measurements. For instance, whereas in Figure 27.3, only 13 per cent of all respondents in the richest income quintile have at least one unmet need, this holds for 25 per cent of those in the poorest quintile. A relative measure of inequality would be the ratio between the two numbers, also known as the Q5/Q1-ratio, which is about one half. Thus the probability of unmet need is only half as large among the richest as among the poorest 20 per cent of the popula- 


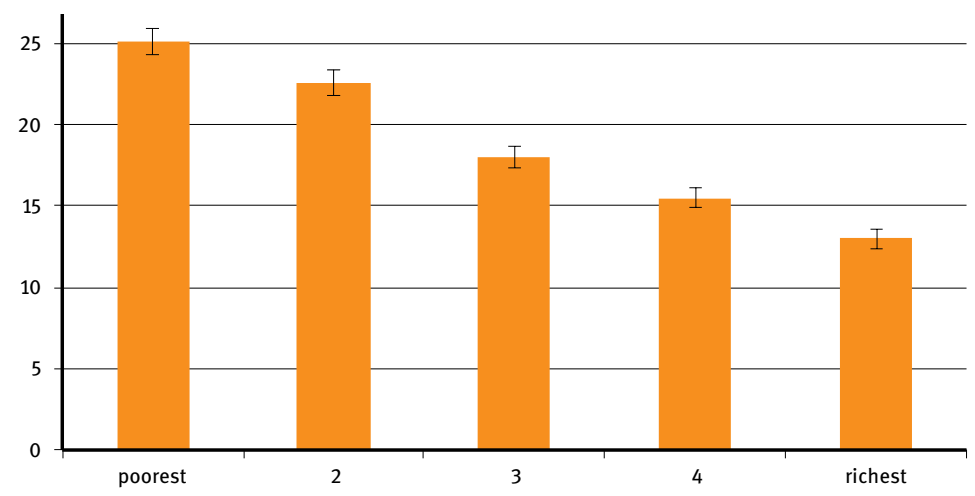

a) Proportion of respondents with at least one unmet need

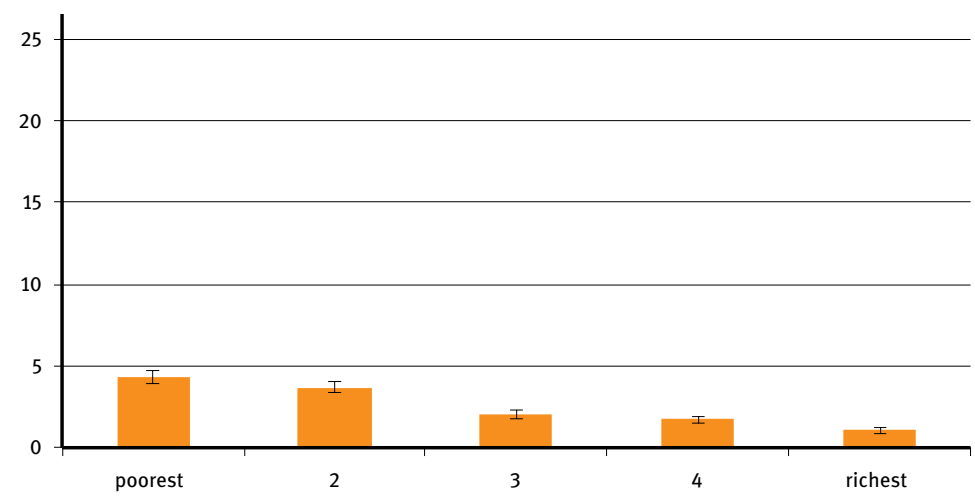

b) Proportion of respondents with catastrophic OOP health expenses

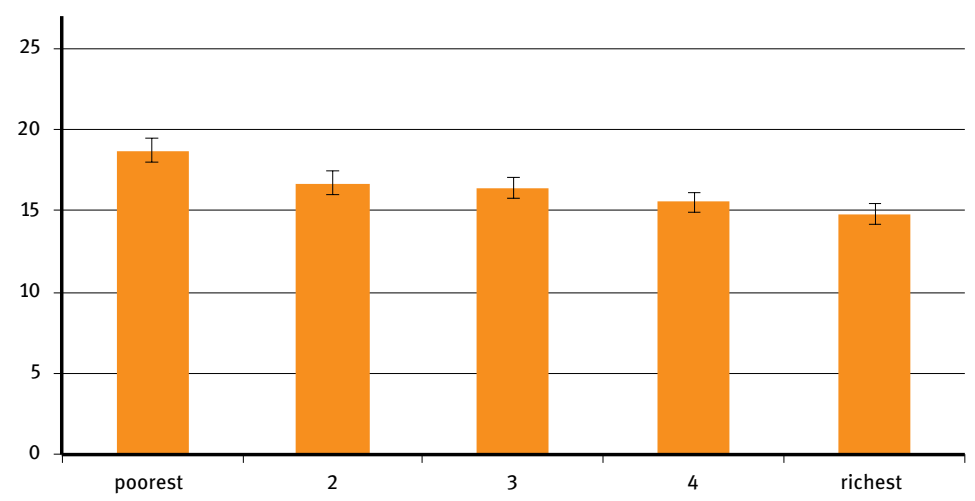

c) Proportion of respondents dissatisfied with basic $\mathrm{HI}$ coverage

Figure 27.3: Average of health insurance coverage indicators by within-country income quintile; vertical lines show 95 per cent confidence intervals

Notes: $\mathrm{N}=63,966$

Source: SHARE Wave 5 release 0 , author's own computations 
tion. Since higher proportions of our indicator variables are worse, it is more convenient to consider the inverse, i.e. the Q1/Q5-ratio, which indicates how much more likely the poor are to suffer from lack of access or health insurance coverage. Ratios above 1 indicate pro-rich inequalities, and the larger the ratio, the larger the inequality. For catastrophic health expenses, this ratio is about four, and for health insurance satisfaction it is approximately 1.2. Thus relative inequality is smallest with respect to health insurance dissatisfaction and largest with respect to catastrophic health care expenses.

An absolute measure of inequality is the Q1/Q5-difference, which shows the percentage point difference in having at least one unmet need etc., between the poorest and the richest income quintile. Using the numbers shown in Figure 27.3, I find that absolute inequality is largest for unmet need and smallest for catastrophic health care expenses. Obviously, the relative and absolute measures can come to very different conclusions as to which is the domain with largest inequalities, and it is beyond the scope of this chapter to review the voluminous literature that has been written on these differences (see e.g. Asada 2010). In the following, I will report only the Q1/Q5 difference as an absolute measure of inequality because it is invariant to the definition of the outcome variable. That is, whereas one could change the Q1/Q5-ratio simply by arbitrarily studying differences in satisfaction rather than dissatisfaction with health insurance coverage, the Q1/ Q5-difference does not change (except for the sign, which is trivial). Since there is no natural way to order the proportions reporting unmet need etc. I use the absolute measure here. A disadvantage is that this measure is heavily influenced by absolute levels of the outcome variable, that is, countries with large levels of unmet need also tend to show large absolute inequalities.

Table 27.2 shows, for each country in the SHARE Wave 5 data, the absolute inequality in our health care access and insurance indicators. Positive numbers reflect pro-rich inequalities and larger numbers mean larger inequalities. Countries are ranked by the first indicator (inequality in unmet need). Statistically significant pro-rich inequalities according to at least one of the three indicators can be found in all countries and almost all of the indicators are significantly different from zero. This confirms that social inequalities in access to care and health care coverage are a widespread phenomenon also in European countries.

Generally, the three measures of inequality are moderately correlated (correlation coefficients between 0.44 and 0.63 ). Consistently large inequalities can be found in Israel, Estonia, and Italy. This is not very surprising because of the absolute levels of unmet need etc. in those countries. For instance, respondents in the poorest Estonian quintile are 25.4 percentage points more likely to report at least one unmet need, 10.9 percentage points more likely to face catastrophic health care expenses, and 4.2 percentage points more likely to be dissatisfied 
with their health insurance coverage than in the richest quintile. In contrast, in Slovenia and Switzerland, there are practically no poor-rich differences in unmet need and dissatisfaction with health insurance coverage. However, with respect to facing catastrophic health care expenses, Switzerland belongs to the most socially unequal societies.

Table 27.2: Absolute inequality in access to care and health insurance coverage (Q1/Q5-differences), by country

\begin{tabular}{lcll}
\hline Country & Unmet need & $\begin{array}{l}\text { Health care } \\
\text { expenses }\end{array}$ & $\begin{array}{l}\text { Dissatisfaction } \\
\text { with HI coverage }\end{array}$ \\
\hline Israel & $40.0^{\star \star \star}$ & $10.7^{\star \star \star}$ & $13.1^{\star \star \star}$ \\
Estonia & $25.4^{\star \star \star}$ & $10.9^{\star \star \star}$ & $4.2^{\star}$ \\
Spain & $23.8^{\star \star \star}$ & $-1.7^{\star \star \star}$ & $2.8^{\star \star}$ \\
Italy & $14.8^{\star \star \star}$ & $7.3^{\star \star \star}$ & $3.9^{\star}$ \\
Sweden & $11.8^{\star \star \star}$ & $3.1^{\star \star \star}$ & 0.0 \\
Luxembourg & $11.6^{\star \star \star}$ & $0.9^{\star \star \star}$ & -0.2 \\
Germany & $10.7^{\star \star \star}$ & $3.4^{\star \star \star}$ & 1.6 \\
Austria & $10.6^{\star \star \star}$ & $6.8^{\star \star \star}$ & $3.3^{\star \star}$ \\
Czech Republic & $8.4^{\star \star \star}$ & $3.8^{\star \star \star}$ & $5.9^{\star \star \star}$ \\
France & $5.7^{\star \star \star}$ & $1.6^{\star \star \star}$ & $4.7^{\star \star \star}$ \\
Netherlands & $5.7^{\star \star \star}$ & $1.2^{\star \star \star}$ & $6.7^{\star \star \star}$ \\
Belgium & $5.2^{\star \star \star}$ & $6.7^{\star \star \star}$ & $3.1^{\star \star \star}$ \\
Denmark & $5.0^{\star \star \star}$ & $2.8^{\star \star \star}$ & 2.0 \\
Slovenia & 0.4 & $2.6^{\star \star \star}$ & 0.6 \\
Switzerland & 0.3 & $6.4^{\star \star \star}$ & 1.3 \\
\hline
\end{tabular}

Significance: ${ }^{\star \star \star}=1 \% ;{ }^{\star \star}=5 \% ;{ }^{*}=10 \%$

Notes: Positive values indicate pro-rich inequalities, $\mathrm{N}=23,392$

Source: SHARE Wave 5 release 0 , author's own computations

\subsection{Unequal access to health care: directions for future research}

Access to health care is a key dimension of social inclusion. In this chapter, I have studied subjective unmet need, catastrophic health care expenses and dissatisfaction with health insurance coverage as measures of access to health care among European elders. I have shown that unmet health care needs and insufficient health insurance coverage still exist among European elders and they vary widely across countries. Among the countries in our sample, the most serious deficiencies can be found in Eastern and Southern European countries, espe- 
cially in Estonia and Italy, and in Israel. (As an aside: it is very unfortunate that we have no information on Greece, which was part of SHARE in earlier waves but could not continue data collection due to the financial crisis.) Generally, insufficient access and lack of insurance coverage are most prevalent in relatively poor countries, where health expenditures are low, and in countries with large income inequalities, i.e. where income redistribution tends to be weak. Thus general notions of social fairness and equity appear to be related to the access to health care that is given to the older population.

Finally, I found that health insurance coverage and access to care are socially graded in practically all countries. Specifically, I have concentrated on income-related inequity, and it is plausible to assume that such inequalities contribute to social inequalities in health status. Previous cross-national analyses of differences in health inequalities have concentrated on social gradients in individual determinants of health linked with social status, such as health behaviour (such as smoking) but often neglected access to care as an important pathway from low social status to poor health. Using the results shown in this chapter as starting point, future research based on the SHARE data can fill this important research gap.

\section{References}

Asada, Yukiko (2010): “On the choice of absolute or relative inequality measures”. In: Milbank Quarterly 88. No.4, p. 616-622.

Jürges, Hendrik (2009): "Healthy minds in healthy bodies: an international comparison of education-related inequalities in physical health among older adults". In: Scottish Journal of Political Economy 56. No.3, p. 296-320.

Jürges, Hendrik (2010): "Health inequalities by education, income and wealth: a comparison of 11 European countries and the US". In: Applied Economics Letters 17. No.1, p. 87-91.

OECD (2014): "Health expenditure and financing: health expenditure indicators", OECD Health Statistics. DOI: http://dx.doi.org/10.1787/data-00349-en.

Wilkinson, Richard, Pickett, Kate (2009): The spirit level: why equality is better for everyone. London: Penguin.

Woodward, Alistair, Kawachi, Ichiro (2000): “Why reduce health inequalities?”. In: Journal of Epidemiology and Community Health 54, p. 923-929.

Wyszewianski, Leon (1986): “Financially catastrophic and high-cost cases: definitions, distinctions, and their implications for policy formulation”. In: Inquiry 23. No.4, p. 382-394. 